\title{
EDITORIAL
}

\section{Powder Diffraction and the Denver X-Ray Conference}

In order to better serve the X-ray analysis community, Powder Diffraction and the Organizing Committee of the Denver X-ray Conference have agreed to a collaboration that will result in increased services for the subscribers of Powder Diffraction and authors of Advances in X-ray Analysis, the proceedings of the Denver X-ray Conference. Powder Diffraction is a quarterly journal published by the International Centre for Diffraction Data through the American Institute of Physics (AIP). The International Centre for Diffraction Data, as publishers of Powder Diffraction and sponsor of the Denver X-ray Conference, will facilitate the collaboration.

Starting with this issue, Powder Diffraction will annually publish the advance program of the Denver X-ray Conference (DXC). The Denver X-ray Conference is the largest annual conference in the world dedicated to the fields of $\mathrm{X}$-ray analysis. This year's conference will be the 52nd Annual Denver X-Ray Conference held at the Denver Marriott Tech Center Hotel in Denver, Colorado. Included with the on-line edition of Powder Diffraction will be active links to both the DXC authors and DXC titles enabling subscribers of Powder Diffraction to search by author or subject for the $\sim 125$ presentations made at the conference. Abstracts will be available in hardcopy to conference attendees.

Proceedings of the conference will continue to be published in an annual issue of Advances in X-ray Analysis and on the IXAS website www.ixas.org. However, as a result of the collaboration, the first quarterly issue of Powder Diffraction (January 2004) will be devoted to select advance publications from the proceedings. These publications will be selected by the Denver X-ray Conference Organizing Committee, as representative of the highest quality publications in X-ray analysis and materials characterization. These papers can cover a range of subjects such as X-ray diffraction, X-ray fluorescence, or special topics in X-ray analysis.
In 2004, an increase will be added to the subscription fee of Powder Diffraction, so that subscribers of Powder Diffraction who receive print or joint print and online versions may also receive the CD-ROM of Volume 47, Advances in $X$-Ray Analysis. This will effectively double the number of articles annually available to Powder Diffraction subscribers at a fraction of the cost. This collaboration significantly increases the circulation for the authors in Advances in X-ray Analysis. This service will start in 2004 since Advances in $X$-Ray Analysis is typically published in the year following the conference.

It is our hope and desire that this collaboration will result in increased exposure of the best of X-ray analysis to the broader international community.

Tim Fawcett Executive Director $I C D D$

Note from Editor-in-Chief:

Dr. Tim Fawcett is the Executive Director of the International Centre for Diffraction Data. He obtained a Ph.D. degree from Rutgers University and joined Dow Chemical Co., worked in the X-ray diffraction facility in 1979. Dr. Fawcett has extensive management experience at Dow including the management of the Analytical Sciences Analysis Laboratory in 1979-1989 and the Ceramics and Advanced Materials Laboratories in 1989-1996. He was the Sr. Research Manager of Dow's Advanced Technologies and Inorganic Coating Group in 1996-2001. Dr. Fawcett research interests include X-ray diffraction and crystallography, inorganic and analytical chemistry, and advanced materials.

Ting C. Huang Editor-in-Chief 